University of Nebraska - Lincoln

DigitalCommons@University of Nebraska - Lincoln

2009

\title{
Hispanic Immigration to the United States
}

Örn B. Bodvarsson

St. Cloud State University, obbodvarsson@stcloudstate.edu

Hendrik F. Van den Berg

University of Nebraska-Lincoln, hvan-den-berg1@unl.edu

Follow this and additional works at: https://digitalcommons.unl.edu/econfacpub

Part of the Economics Commons

Bodvarsson, Örn B. and Van den Berg, Hendrik F., "Hispanic Immigration to the United States" (2009). Economics Department Faculty Publications. 45.

https://digitalcommons.unl.edu/econfacpub/45

This Article is brought to you for free and open access by the Economics Department at DigitalCommons@University of Nebraska - Lincoln. It has been accepted for inclusion in Economics Department Faculty Publications by an authorized administrator of DigitalCommons@University of Nebraska - Lincoln. 


\title{
Hispanic Immigration to the United States
}

\author{
Örn B. Bodvarsson \\ Department of Economics, St. Cloud State University, \\ 720 Fourth Avenue South, St. Cloud, MN 56301, USA; \\ email obbodvarsson@stcloudstate.edu (Corresponding author)

\section{Hendrik Van den Berg} \\ Department of Economics, University of Nebraska, 880489, \\ Lincoln, NE 68588-0489, USA; email hvan-den-berg1@unlnotes.unl.edu
}

\begin{abstract}
This chapter presents some of the exceptional characteristics of recent Hispanic immigration to the United States. In 2005, there were nearly 40 million Hispanic immigrants and descendants of Hispanic immigrants living in the U.S. The assimilation experience of this large cultural group does not seem to be following the path past immigrants to the U.S. followed. Most third generation Hispanics in the U.S. still find themselves with income and education levels below the U.S. averages. Most forecasts predict that about 60 million Hispanics and Hispanic-Americans will be living in the U.S. by 2030.
\end{abstract}

The persistent inflow of Hispanic immigrants threatens to divide the United States into two peoples, two cultures, and two languages.

Samuel Huntington $(2006)^{1}$

Americans living in smaller U.S. cities like Little Rock, Arkansas, Raleigh, North Carolina, and Omaha, Nebraska, are often surprised to learn that there is a Mexican Consulate in their city. In fact, aside from the obvious locations of consulates, such as New York City, Chicago, and Los Angeles, in 2007 there were 47 Mexican Consulates in cities throughout the U.S. This proliferation of Mexican diplomatic offices across the U.S. reflects the extraordinary increase in Mexican immigrants living in the U.S. There are about 11 million Mexican immigrants in the United States, and another ten million U.S. born Mexican Americans. Mexicans make up nearly two-thirds of the overall group of Hispanic immigrants in the United States, and Hispanics, in turn, account for nearly one-half of all foreign-born residents in the United States.

The rapid growth of immigration to the U.S. from Latin America has increased the overall Hispanic population of the U.S. The social group commonly referred to as Hispanics includes all immigrants from Latin American countries and their offspring. So 
Table 1. Estimates of Hispanic population in the United States: 2000 and 2005

\begin{tabular}{lrrrr}
\hline & Census 2000 & $\%$ & $\begin{array}{r}\text { 2005 } \\
\text { Community } \\
\text { survey }\end{array}$ & $\%$ \\
\hline Total Hispanic & & & $41,926,302$ & 100.0 \\
Mexican & $35,305,818$ & 100.0 & $26,784,268$ & 63.9 \\
Puerto Rican & $20,640,711$ & 58.5 & $3,794,776$ & 9.1 \\
Cuban & $3,406,178$ & 9.6 & $1,462,593$ & 3.5 \\
Dominican & $1,241,685$ & 3.5 & $1,135,756$ & 2.7 \\
Central American & 764,945 & 2.2 & $3,114,877$ & 7.4 \\
Costa Rican & $1,686,937$ & 4.8 & 111,978 & 0.3 \\
Guatemalan & 68,588 & 0.2 & 780,191 & 1.9 \\
Honduran & 372,487 & 1.1 & 466,843 & 1.1 \\
Nicaraguan & 217,569 & 0.6 & 275,126 & 0.7 \\
Panamanian & 177,684 & 0.5 & 141,286 & 0.3 \\
Salvadoran & 91,723 & 0.3 & $1,240,031$ & 3.0 \\
South American & 655,165 & 1.9 & $2,237,960$ & 5.3 \\
Argentinean & $1,353,562$ & 3.8 & 189,303 & 0.5 \\
Bolivian & 100,864 & 0.3 & 68,649 & 0.2 \\
Chilean & 42,068 & 0.1 & 105,141 & 0.3 \\
Colombian & 68,849 & 0.2 & 723,596 & 1.7 \\
Ecuadorian & 470,684 & 1.3 & 432,068 & 1.0 \\
Peruvian & 260,559 & 0.7 & 415,352 & 1.0 \\
Uruguayan & 233,926 & 0.7 & 51,646 & 0.1 \\
Venezuelan & 18,804 & 0.1 & 162,762 & 0.4 \\
Other & 91,507 & 0.3 & 89,443 & 0.2 \\
All Otherc & 57,532 & 0.2 & $3,396,072$ & 8.1 \\
\hline & $6,211,800$ & 17.6 & &
\end{tabular}

a Table 3 from Suro (2002).

b Pew Hispanic Center tabulations of the Census Bureau's 2005 American Community Survey, reported in "A Statistical Portrait of Hispanics at Mid-Decade," downloaded from http://pewhispanic.org/docs/December 1, 2007

c This category includes Hispanics from other Caribbean countries and people who define themselves as Hispanics or Latinos without specifying any Hispanic country. Such general classifications are more common on voluntary Census returns than in the Community Survey interviews.

large has been recent Hispanic immigration to the U.S. that, in 2002, Hispanics passed African Americans as the largest minority ethnic group in the U.S. In that year, the U.S. Census Bureau estimated that there were about 37 million Hispanics in the U.S., compared to 36.1 million African Americans. ${ }^{2}$ Table 1 details the 2000 U.S. Census data on the Hispanic population.

A controversial book by Samuel Huntington (2004) entitled Who Are We? The Challenges to America's Identity reflects the sentiments of some Americans with regard to the large inflow of Spanish speaking immigrants. As the sample quote by Huntington shown at the head of this chapter suggests, Huntington does not view the massive Hispanic immigration to the U.S. favorably. He argues that Hispanic immigrants are less

2 As reported in the Associated Press (2003), Hispanics Outnumber Blacks in U.S. Minority Population. 
likely than previous immigrants to the U.S. to assimilate, learn English, and reach income parity with native-born Americans. Huntington is not alone in his views. Hispanic immigration seems to be the focus of the increasingly active opposition to immigration in the U.S., not unlike the anti-immigrant movement in Germany that focuses on the rapid growth of Turkish immigration to Germany or the French opposition to further immigration from North Africa. Sudden large inflows of immigrants from a single foreign culture have always led to resistance in the destination country.

There is little doubt that the current wave of Hispanic immigration to the United States will bring major economic and social changes to both the source and destination countries. It will be a challenge for the U.S. to devise a set of policies to effectively deal with this disruptive but potentially beneficial immigration episode. The difficulties the U.S. Congress faced when it tried to enact practical legislation to modify the country's poorly designed immigration system in 2006 and 2007 underscores the complexity of the issue and the many conflicting interests and views that must be dealt with. From a social scientist's perspective, we can learn a lot from the U.S. experience with Hispanic immigration. Other countries face similar movements of people and clashes of cultures, as evidenced by the conflicts surrounding the growth of the non-Christian population in many European countries. This chapter summarizes what we know about Hispanic immigration to the United States, and it points to where we need further research and analysis.

\section{The Characteristics of Hispanic Immigration}

Immigration to the United States has gone through many different phases. The latest phase, which covers the years since the 1960s, is characterized by a sharp shift in immigration source countries from Europe to Latin America and Asia. Hispanics make up the largest share of new arrivals. Nearly half of all foreign-born persons currently living in the U.S. came from Mexico, Central America, South America, or the Spanish-speaking Caribbean countries. Table 2 provides detailed figures for 2005.

Over $30 \%$ of foreign-born Americans are natives of Mexico. This is a very high share for one single country. The concentration of the sources of immigration has fueled fears that Hispanics will establish a permanent parallel culture in the United States rather than assimilate into the dominant culture. Recall, again, Huntington's words at the start of the chapter. Many of those who expect Mexican and other Hispanic immigrants to eventually assimilate like all other immigrant groups have done in the past nevertheless still fear that the massive inflow of people from one single foreign country will substantially change American culture.

It is interesting to ask why reactions to Hispanic immigration are so much less favorable than reactions to recent immigration from Asia. Asian immigration to the U.S. does not seem to generate the same emotional response among the native U.S. population that Hispanic immigration does. This is surprising because Asian immigration to the U.S. has grown just as fast as immigration from Hispanic countries. Perhaps Asian 
Table 2. Country of birth of foreign-born living in the United States the 20 largest sending countries: 2005

\begin{tabular}{lrrllc}
\hline & Number & $\begin{array}{l}\text { Percent of all } \\
\text { Foreign-born }\end{array}$ & & Number & $\begin{array}{c}\text { Percent of all } \\
\text { Foreign-born }\end{array}$ \\
\hline Country & & & Country & & \\
Mexico & $10,993,851$ & 30.7 & Guatemala & 644,669 & 1.8 \\
Philippines & $1,594,805$ & 4.5 & Germany & 626,504 & 1.8 \\
India & $1,410,731$ & 3.9 & Jamaica & 579,241 & 1.6 \\
China & $1,202,923$ & 3.4 & Colombia & 554,821 & 1.6 \\
Vietnam & $1,072,881$ & 3.0 & Haiti & 483,748 & 1.4 \\
Korea & 993,883 & 2.8 & Poland & 449,158 & 1.3 \\
El Salvador & 988,014 & 2.8 & Honduras & 387,002 & 1.1 \\
Cuba & 902,448 & 2.5 & Italy & 385,973 & 1.1 \\
Canada & 830,300 & 2.3 & Russia & 381,169 & 1.1 \\
Dominican Republic & 708,455 & 2.0 & Peru & 371,980 & 1.0 \\
Region/ethnicity & & & & & \\
Total Hispanic & $16,840,774$ & 47.1 & & & \\
South and East Asia & $8,385,165$ & 23.4 & & & \\
Middle East & $1,220,776$ & 3.4 & & & \\
All Other & $9,322,888$ & 26.1 & & & \\
Total foreign born & $35,769,603$ & 100.0 & & & \\
\hline Sourc: Pew Hispan & & & & & \\
\hline
\end{tabular}

Source: Pew Hispanic Center (2006), “Tabulations using data from the 2005 American Community Survey," October 2006.

immigration seems less threatening because its sources are spread evenly among several distinctive cultures. For example, the Philippines, India, China, Vietnam, and South Korea each account for between 3 and $4.5 \%$ of foreign-born Americans. Another possible factor is that a greater percentage of Asian immigrants are highly educated professionals while the great majority of Hispanic immigrants are laborers with less than high school education.

Another reason that Hispanic immigration may generate more openly expressed concerns is that it has been highly concentrated in a few states such as California, New York, Florida, and Texas. This geographic concentration effectively amplifies the cultural influence of immigrants in those areas. This is not to say that all Hispanic immigration to these states is from the same countries; Mexican immigrants favor California and Texas, while immigrants from Caribbean countries such as Cuba and the Dominican Republic most often settled in Florida and New York, respectively. Central Americans have favored California. Also, in recent years Hispanic immigrants have increasingly settled in Southern and Midwestern states, where food processing and other manufacturing are concentrated. It is not clear yet whether this wider dispersion of Hispanic immigrants merely makes new regions of the U.S. more aware of immigration or whether it reduces the fear that Hispanic immigration will establish a permanent parallel culture in the U.S. 

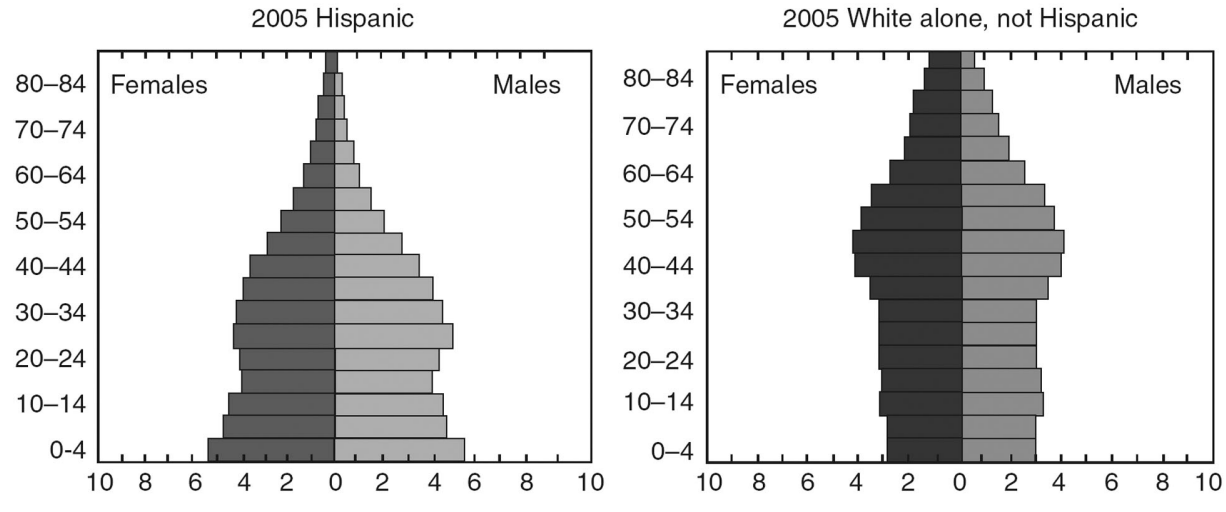

2005 Hispanic Foreign Born
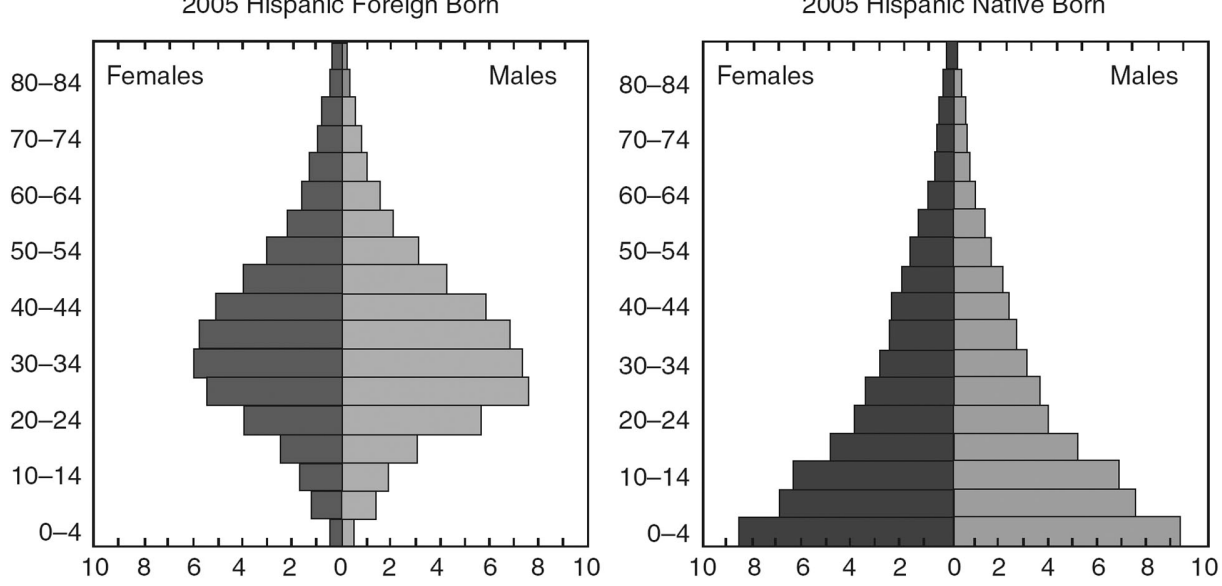

Figure 1. Population pyramids for Hispanic and non-Hispanic populations in the U.S.: 2005.

Hispanic immigrants are disproportionately young and working aged. Figure 1 shows the population profiles for foreign-born Hispanics in the lower left-hand diagram and non-Hispanic Americans in the upper right-hand diagram. Compared to the overall U.S. population, very few foreign-born Hispanics are either very young or very old. The great majority of foreign-born Hispanics are of working age. This implies that, all other things equal, Hispanic immigrants are likely to be self-supporting and productive. On the other hand, the lower right-hand diagram in Figure 1 makes it obvious that Hispanic families have more children than Americans, on average. Hence, the U.S.-born Hispanic population is relatively young. With the youth of the native-born Hispanic population, the population profile of the combined foreignborn and native-born Hispanic population in the U.S. is, on average, younger than the overall U.S. population. In a sense, Hispanic immigration has mitigated, at least in part, the problems associated with the ageing of the U.S. population. Compared to most other high income countries, population ageing is not nearly as serious a problem in the U.S. 


\section{Assimilation}

Historical evidence suggests that immigrants to the U.S. have almost always assimilated within one or two generations. Even at the previous height of immigration at the start of the twentieth century, when the foreign-born population surpassed $15 \%$ of the total population, immigrants quickly moved up to the average income and education levels of the native U.S. population. Blau's (1980) often-referenced study used detailed data for the late nineteenth and early twentieth centuries to determine that immigrants quickly caught up to native-born Americans in income. Equally well-known is Chiswick's (1978) study, which used 1970 Census data to show that immigrants' earnings caught up to, and then exceeded, native-born Americans' average incomes after just 10 or 15 years. These average outcomes do not describe all immigrants a century ago, of course. There were high rates of return immigration after World War I and during the Great Depression, and many immigrants and their descendants remained poor. However, today even the average indicators for immigrant assimilation suggest that the traditional myth of immigrants as anxious to assimilate and become "American" as quickly as possible may be inaccurate.

Perlmann and Waldinger's (1997) statistical analysis shows that in the 1990s the children of immigrants still lagged substantially behind the rest of the U.S. population in education, income, and in terms of other socioeconomic indicators. Perlmann and Waldinger's data on recent immigrants in the U.S. suggest that U.S. immigration from Latin America, and from Mexico in particular, is the main cause of the change in assimilation rates. When they eliminate Mexican immigrants from their sample, they find that the socioeconomic disadvantage among children of immigrants vanishes. Hence, they conclude that Mexican immigrants are somehow different from earlier immigrants to the U.S.

\subsection{Hispanics' Slow Assimilation}

Table 3 provides further insight into how Hispanic immigration differs from immigration overall and to other specific groups of immigrants. Notice that, compared to the native population or native households, immigrants and immigrant households from Mexico, Central America, the Caribbean, and South America all have higher concentrations in the lower income categories. Note also that Asian immigrants and immigrant households have higher median incomes and greater concentrations in higher-income brackets compared to the native-born American population and households. Hence, the data indeed suggest that Hispanic immigrants, on average, do not raise their economic status very quickly. Of course, assimilation is never a matter of a few years; it normally takes at least a generation. Hence, the data in Table 3 may not be a good indication of assimilation for the large numbers of Hispanic 


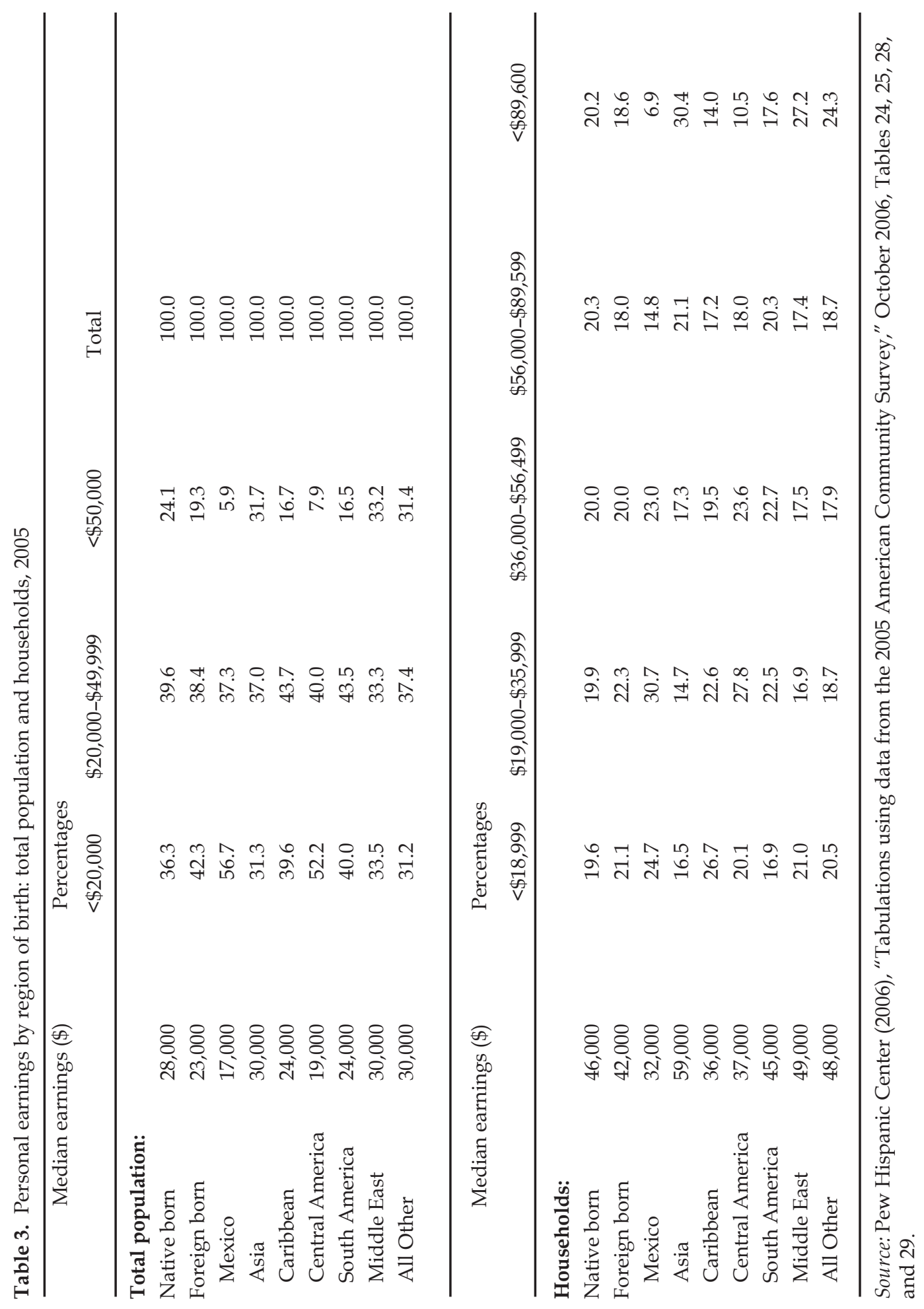


immigrants to the U.S. Also, there are many other indicators that could be used to show how quickly immigrants assimilate, such as language fluency, mixed marriages, housing, education, and university graduation rates, and we will examine these alternative indicators below.

Research on the assimilation of Mexican Americans in the U.S. shows that new immigrants from Mexico and other Hispanic countries earn substantially less than U.S. natives. But, more ominously, studies such as Livingston and Kahn (2002) find that second generation Mexican Americans only partially catch up to the U.S. average, and third generation Mexican Americans show no further progress at all in catching up. Borjas $(1985,1994)$ uses evidence of the stalled economic progress after the second generation to argue that "the huge skill differentials observed among today's foreign-born groups become tomorrow's differences among American-born ethnic groups." 3 In short, there is evidence that a permanent gap between Hispanics and other Americans may be in the making.

Trejo $(1997,2003)$ looks at the causes of the lack of income growth for Mexican immigrants, and he concludes that the differences in income between Mexican Americans and other U.S. residents are largely explained by differences in human capital. In his studies, Trejo provides evidence showing that Mexican Americans do not continue catching up between the second and third generations because they do not continue to increase their relative levels of human capital after the second generation.

Duncan and Trejo (2006) survey the various studies of assimilation by Mexican Americans, and they report that between the first and second generations, average schooling rises by almost four years, and incomes rise by $30 \%$. But then advancement stops, and third generation Mexican Americans still have 1.3 fewer years of education than the average American, and incomes are still about 25\% lower. Suro and Passel (2003) examine income and education attainment and find the same pattern of rapid advancement from the first to the second generations of Hispanic immigrants, followed by little change from the second to the third generations. Table 4 summarizes the data from a special survey by the U.S. Census Bureau.

When it comes to English language skills, however, Suro and Passel (2003) find a continued improvement in English proficiency from the second to the third generations. While fewer than half of all second generation Hispanic immigrants live in households where English is the dominant language, nearly $80 \%$ of third generation Hispanics do. Table 5 details the English proficiency of Hispanics. Also, Suro and Passel show that Hispanics do assimilate socially after the second generation. Only $8 \%$ of first-generation Hispanics marry someone outside their ethnic group, nearly one-third of second-generation immigrants do, and $57 \%$ of third-generation Hispanic immigrants do. Therefore, in terms of this indicator, assimilation is clearly occurring.

Blau and Kahn (2005) use the U.S. Census Bureau's Current Population Survey data for 1994-2003 to distinguish the assimilation of male and female Mexican Americans in order to determine whether gender differences can explain the slow assimilation in 


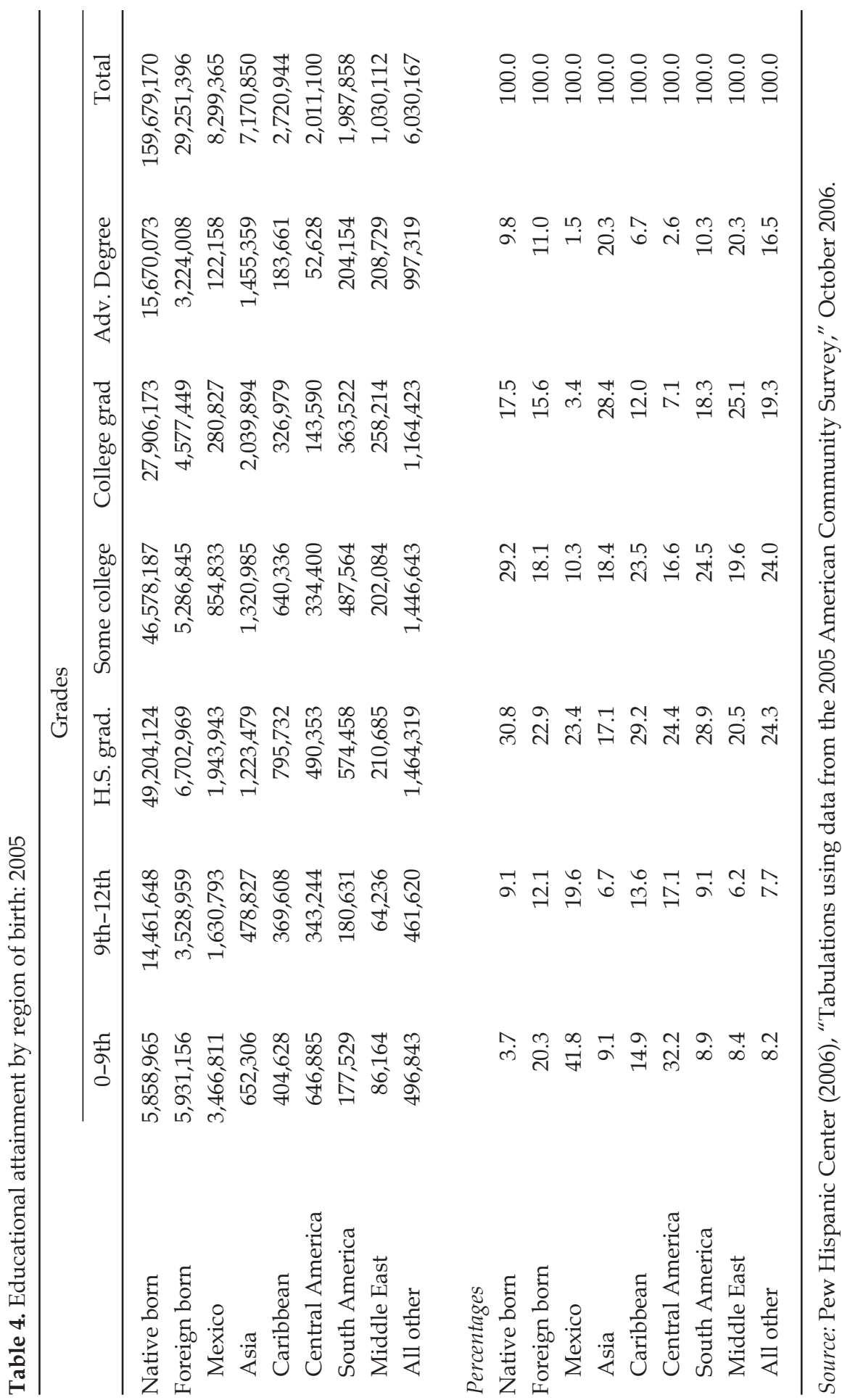




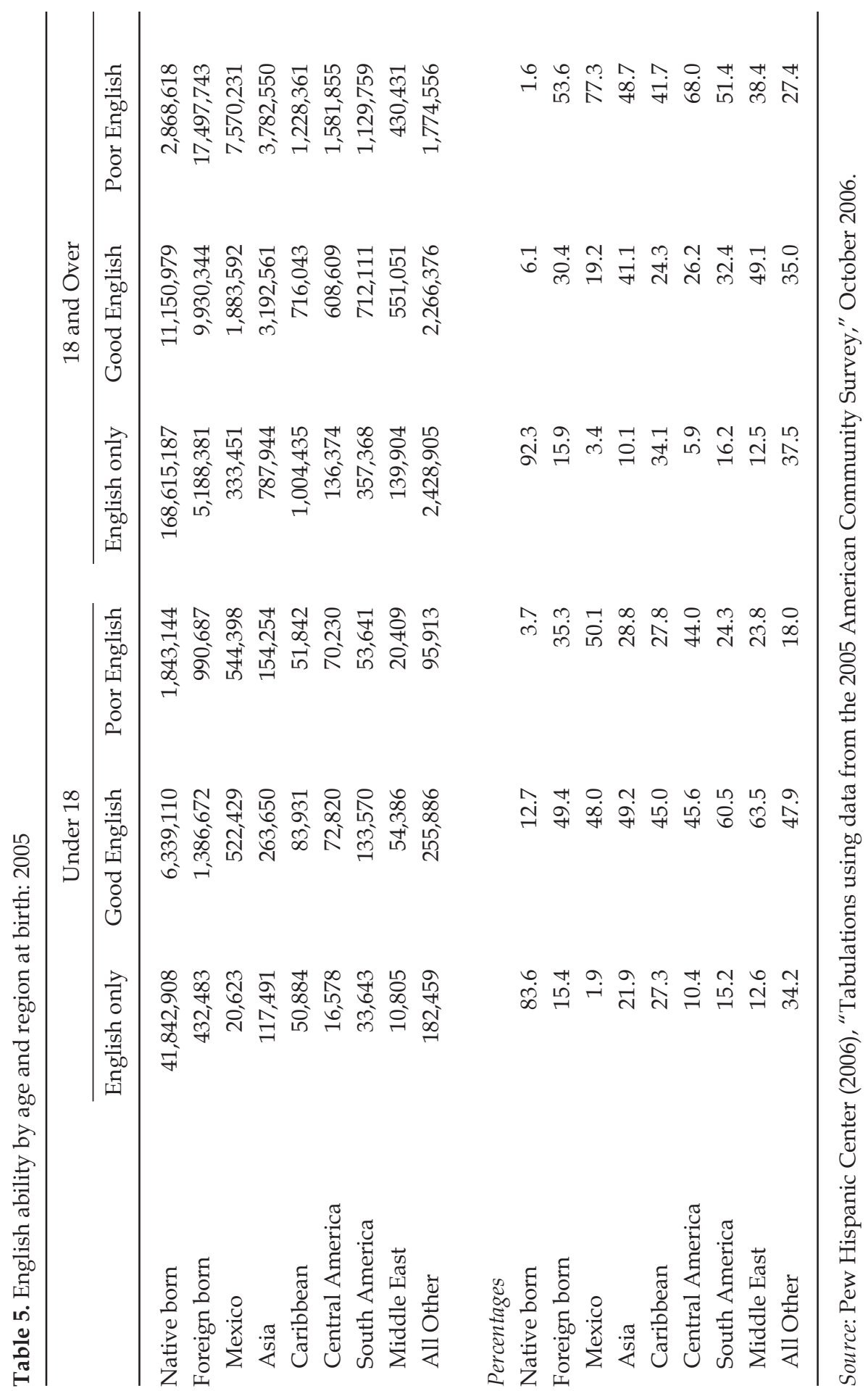


terms of income. They find that immediately after immigrating to the U.S., Mexican male and female immigrants both work fewer hours per week than their average U.S. counterparts. But, in terms of hours worked they catch up within 20 years. Wages received remain far below the national average for Mexican immigrants, however, and this differential shrinks only with the second generation Mexican Americans for both men and women, largely because of increased levels of education. However, as other studies have found, there is little further improvement in education, labor supply, or wages beyond the second generation.

Mexican immigrants are more likely to be married than Americans overall, and fertility levels also exceed U.S. averages for women. Marriage rates remain above the U.S. average through the third generation, and while female fertility declines by the third generation, it remains above the U.S. average. Blau and Kahn (2005) conclude that Mexican American families continue to exhibit a family structure more similar to Mexican families than American families. Again, it appears as though Mexican Americans do not assimilate as fast as previous immigrant groups have done. Table 6 presents data from the Census Bureau's 2005 community Survey that support the conclusions by Blau and Kahn.

\subsection{Further Reasons Why Hispanic Assimilation is Slow}

Hispanic immigrants appear to be less entrepreneurial than other immigrant groups or Americans in general. Combined with the lower levels of education of Hispanic immigrants, the below average levels of entrepreneurial activity further reduce Hispanics' access to the traditional routes that past immigrants have used to quickly reach average U.S. income levels. Fairlie and Woodruff (2006) find that only 6\% of Mexican immigrants to the United States are self-employed. This outcome contrasts sharply with other immigrant groups to the U.S., which all exhibit self-employment rates more similar to native country self-employment rates. Interestingly, Mexican immigrants' low rate of self-employment also contrasts sharply with the very high rate of self-employment in Mexico. Mexico has the highest self-employment rate of 28 OECD countries, and it is ranked fourth among a larger sample of 41 countries by the Global Entrepreneurship Monitor (2003). ${ }^{4}$ Yuengert (1995) reports that across all immigrant groups, self-employment rates are usually positively correlated with native country rates. This relationship does not hold for Hispanic immigrants to the United States, however.

The drastic fall in self-employment when Mexicans and other Hispanics cross the U.S. border begs for an explanation. At the very least, the phenomenon suggests that Mexican American immigrants and their children face barriers to entrepreneurship. Perhaps the lack of self-employment is due to the high percentage of unauthorized immigrants among Hispanic immigrants; unauthorized immigrants do not have ac-

4 Reported in Fairlie and Woodruff (2006). 
Table 6. Family structure of U.S. immigrants by region of birth: 2005

\begin{tabular}{|c|c|c|c|c|c|}
\hline & \multicolumn{3}{|c|}{ Family household } & \multirow[b]{2}{*}{$\begin{array}{r}\text { Non-family } \\
\text { household }\end{array}$} & \multirow[b]{2}{*}{ Total } \\
\hline & Married couple & $\begin{array}{r}\text { Female head } \\
\text { only }\end{array}$ & $\begin{array}{r}\text { Male head } \\
\text { only }\end{array}$ & & \\
\hline Native born & $158,063,089$ & $40,142,786$ & $12,818,558$ & $41,604,783$ & $252,629,216$ \\
\hline Foreign born & $23,367,506$ & $4,463,987$ & $3,165,419$ & $4,772,691$ & $35,769,603$ \\
\hline Mexico & $7,179,023$ & $1,471,870$ & $1,399,503$ & 943,455 & $10,993,851$ \\
\hline Asia & $6,110,777$ & 744,171 & 507,797 & $1,022,420$ & $8,385,165$ \\
\hline Caribbean & $1,675,811$ & 732,483 & 252,695 & 489,803 & $3,150,792$ \\
\hline Central America & $1,385,611$ & 435,377 & 371,817 & 316,521 & $2,509,326$ \\
\hline South America & $1,489,419$ & 357,092 & 235,919 & 353,848 & $2,436,278$ \\
\hline Middle East & 853,719 & 92,373 & 97,132 & 177,552 & $1,220,776$ \\
\hline All Other & $4,673,146$ & 630,621 & 300,556 & $1,469,092$ & $7,073,415$ \\
\hline \multicolumn{6}{|c|}{ Percentages of population } \\
\hline Native born & 62.6 & 15.9 & 5.1 & 16.5 & 100.0 \\
\hline Foreign born & 65.3 & 12.5 & 8.8 & 13.3 & 100.0 \\
\hline Mexico & 65.3 & 13.4 & 12.7 & 8.6 & 100.0 \\
\hline Asia & 72.9 & 8.9 & 6.1 & 12.2 & 100.0 \\
\hline Caribbean & 53.2 & 23.2 & 8.0 & 15.5 & 100.0 \\
\hline Central America & 55.2 & 17.4 & 14.8 & 12.6 & 100.0 \\
\hline South America & 61.1 & 14.7 & 9.7 & 14.5 & 100.0 \\
\hline Middle East & 69.9 & 7.6 & 8.0 & 14.5 & 100.0 \\
\hline All Other & 66.1 & 8.9 & 4.2 & 20.8 & 100.0 \\
\hline \multicolumn{6}{|c|}{ Percentages of households } \\
\hline Native born & 49.2 & 12.4 & 4.1 & 34.3 & 100.0 \\
\hline Foreign born & 55.8 & 13.4 & 7.6 & 23.1 & 100.0 \\
\hline Mexico & 60.2 & 14.9 & 11.7 & 13.3 & 100.0 \\
\hline Asia & 63.3 & 9.2 & 5.2 & 22.2 & 100.0 \\
\hline Caribbean & 42.3 & 24.2 & 6.9 & 26.6 & 100.0 \\
\hline Central America & 49.5 & 19.5 & 12.1 & 18.9 & 100.0 \\
\hline South America & 50.8 & 16.6 & 8.7 & 23.9 & 100.0 \\
\hline Middle East & 60.1 & 7.5 & 7.1 & 25.4 & 100.0 \\
\hline All Other & 51.6 & 9.2 & 3.7 & 35.5 & 100.0 \\
\hline
\end{tabular}

Source: Pew Hispanic Center (2006), "Tabulations using data from the 2005 American Community Survey," October 2006, Tables 15 and 16.

cess to bank financing, they cannot acquire the required permits and licenses to operate businesses, and they cannot use the courts to protect themselves against fraud, theft, and delinquent payments. Or, the lack of self-employment and, presumably, entrepreneurship may itself be a direct result of the slow assimilation of Hispanics into U.S. society.

The low rate of self-employment among Hispanics not only contributes to Hispanics' lack of income mobility, it may also be preventing the U.S. economy from gaining the full growth dividend from immigration. Recall from Chap. 9 that Joseph Schumpeter 
considered the entrepreneur as something of a social deviant because his or her attitude was different from the average member of society. Schumpeter pointed out that entrepreneurs were often recent immigrants because immigrants tend to be less attached to the traditions of society and, therefore, less reluctant to innovate. Furthermore, through natural selection, immigrants tend to be people who are more willing to take risks in exchange for potential future gains. Chiswick (2000) wrote that immigrants self-select in terms of personal characteristics favorable to economic growth: "The greater the out of pocket (direct) costs of migration and return migration, the greater the effect of ability on lowering the costs of migration, and the smaller are the wage differences by skill in the lower income origin than in the higher income destination." International migration, therefore, provides a natural selection process that distinguishes exceptionally adventuresome and enterprising people.

This discussion suggests that unless the U.S. finds ways to reduce the barriers to entrepreneurship that seem to apply disproportionately to Hispanic immigrants, the U.S. economy will suffer. Assimilation will be slower than necessary, which means that Hispanic immigrants will add less to U.S. output and demand. The barriers to entrepreneurship that Hispanics seem to face imply that the U.S. economy will continue to miss the full growth effect of immigration.

Finally, Lazear (2006) blames Hispanic immigrants' slow assimilation on the way the U.S. has designed its immigration policies. He argues, first of all, that U.S. immigration policy results in a very large proportion of Mexicans and Hispanics entering the country either illegally because of Latin America's proximity to the U.S. and lax U.S. border enforcement. And when Hispanics immigrate legally, it is almost always under the family reunion criterion rather than on the basis of their skills, educational attainment, or job prospects. Both unauthorized immigration and family reunion tend to promote settlement in ethnic enclaves. According to Lazear, the large numbers of Hispanic immigrants means that they live in very large enclaves that encourage immigrants to hold on to their own customs longer and assimilate more slowly than other ethnic groups that begin in small enclaves. There are Spanish language newspapers, radio stations, and television stations in nearly all cities where there are Hispanic enclaves. The larger populations in the Hispanic enclaves also result in more second and third generation Hispanics marrying other Hispanics rather than partners with other ethnic backgrounds.

\subsection{Perhaps It Is All a Data Problem}

Duncan and Trejo (2005) suggest a completely different reason why the data shows Hispanic immigrants to have assimilated so slowly. They argue that the census data used in most studies give an inaccurate impression because the children of mixed parents, e.g., when a Mexican American marries a non-Mexican American, are often not reported as being Mexican Americans. Also, the children of mixed couples most likely assimilate much faster, and such children are increasingly unlikely to classify themselves 
in the Census as Hispanics. In other words, the data may be tracing mostly the assimilation histories of the children of parents who assimilated less, in part because they married a spouse from the same ethnic group. The Census data are likely to miss many of the children of the parents that assimilated more quickly and found spouses in other ethnic groups. Hence, true assimilation of Mexican Americans is faster and more complete than the Census data suggest.

In a study that pre-dated many of the recent studies which find that assimilation stagnates after the second generation, Jasso and Rosenzweig (1988) used data that tracks individuals over time rather than the standard Census data to argue that assimilation of Hispanics was not any slower than previous large immigrant groups in the early twentieth century. Their time-series data for individual households indicate faster occupational mobility than the Census data suggest. ${ }^{5}$

\subsection{Political Attitudes of Hispanic Immigrants}

The slower assimilation of Hispanic immigrants may be, in part, the result of the strong ties to their native countries that many immigrants maintain. Such ties are often encouraged by the governments of the native countries. In fact, a number of Western Hemisphere countries have recently changed their national laws to encourage permanent immigrants to maintain ties with their native country. In the past, most countries cut off citizenship when citizens immigrate and acquire citizenship in another country, but in recent years Colombia, Ecuador, Brazil, Mexico, and the Dominican Republic, among others, have changed their laws to permit dual citizenship. Mexico even allows former citizens to reclaim Mexican citizenship after they had lost it by becoming citizens in the United States. In 2004, President Fox asked the Mexican Congress to approve letting millions of Mexican citizens living in the United States vote in the 2006 Mexican presidential election. ${ }^{6}$ The Mexican state of Zacatecas passed a law in 2003 to let the 800,000 Zacatecans who now live in the United States run for local political office. ${ }^{7}$ The President of the Dominican Republic in 2004, himself a former resident of New York, attributed his electoral victory to the huge number of votes by Dominicans living in New York who, like Mexicans living abroad, had gained the right to vote in their native country. ${ }^{8}$

A 2004 Pew Hispanic Center survey of Mexican immigrants who visited a Mexican consulate in the U.S. to apply for a matricula consular, an identity card issued by the Mexican government that helps unauthorized immigrants open a U.S. bank account, acquire medical services in the U.S., and provide proof of age, suggests that

\footnotetext{
5 Jasso and Rosenzweig (1988).

6 Weiner (2004).

7 Authers (2004).

8 Bernstein (2004).
} 
many Mexican immigrants living in the U.S. intend to continue voting in Mexican elections. ${ }^{9}$ Nearly 9 out of $10(87 \%)$ respondents said they would vote in the next elections if they could. Granted, the survey sample was biased; Mexican immigrants who seek a matricula consular are almost always unauthorized immigrants who cannot obtain U.S. identity documents. On average, unauthorized immigrants are less likely to assimilate because they face many barriers to jobs, education, and social organizations. ${ }^{10}$

These suggestions that today's Hispanic immigrants are less likely to assimilate than earlier U.S. immigrants should be kept in perspective, however. The fact is that newly arriving immigrants to the U.S. have always maintained close ties with their native countries. Most immigrant communities a century ago had newspapers in the native languages of immigrants, ethnic food stores and restaurants, and clubs and associations organized along national lines. When radio became a dominant medium in the early twentieth century, foreign language programs were regularly broadcast in cities with significant immigrant enclaves. There was a Hibernian Hall in most cities of the U.S. Northeast where Irish immigrants met. The Sons of Italy sponsored sports and social activities for Italian immigrants in many of the same cities. Of course, many churches and other religious organizations established in the U.S. reflected specific national origins and ethnic traditions. In any case, the high rates of return immigration discussed in Bodvarsson and Van den Berg, The Economics of Immigration (2009), Chapter 10, suggest that in the nineteenth and early twentieth centuries cultural and family ties to the homeland often trumped assimilation.

\section{Geographic Diffusion}

One common characteristic of immigration is that immigrants tend to cluster together in the destination countries, often in what become easily identifiable ethnic communities. In the United States, Hispanic immigrants have tended to also cluster in certain urban areas and certain states. What is also well known is that Hispanic immigrants from specific towns and regions of their native countries cluster together in specific towns and regions in the United States.

\subsection{Networks and Herding}

An accepted explanation for clustering is the presence of network externalities. In the case of immigration, earlier immigrants provide assistance to new immigrants, and previous immigrants can provide trusted information about the destination to other

9 Suro (2005).

10 As quoted in Pascal (1998). 
immigrants. Bauer, Epstein, and Gang (2002) differentiate between network effects and what they call herding behavior. They define immigrant network effects as immigrants deciding "I will go to where my people are, since it will help me." Herding behavior, on the other hand, implies immigrants tell themselves: "I will go to where I have observed others go, because all these others who went before me probably have information that I do not have, even though I would have chosen independently to go elsewhere." Herding behavior effectively assumes that people have little confidence in their own information, and they feel that others' information must be better than theirs. In either case, networks or herding, immigrants from the same source countries tend to concentrate in certain communities, states, or regions. Hispanic immigrants have certainly done this, as suggested in Table 7.

Bauer, Epstein, and Gang examine data for Mexican immigrants to the United States to test for the relative importance of herding and network effects in determining immigrant location decisions. They label as herding the practice of natives from the same local community following fellow community members to specific locations in the U.S. Network externalities are measured by the share of Mexican immigrants in the population of a specific community in the U.S. Bauer, Epstein, and Gang find that both herding and network effects matter; one reinforces the other. The network effect is not linear, however. Network effects expand immigration to a specific community up to where Mexicans account for about $10 \%$ of the community's population, after which the strength of network externalities declines. The network effect is U-shaped, therefore. Herding effects are similarly U-shaped. In addition, network and herding effects are significantly stronger for illegal immigrants and poorly-educated immigrants.

\subsection{Towards the South and the Midwest}

There has been a noticeable diffusion of Hispanic immigrants to a more diverse set of destinations in recent years. Kochlar, Suro, and Tafoya (2005) report that the Hispanic population is growing faster in the Southern states than anywhere else in the United States. Table 8 presents some of these authors' data showing that the highest growth rates of Hispanic immigration were in Southern states. They describe how the economies in the South and the Midwest are changing rapidly, and they are growing rapidly as well: "Such conditions have acted as a magnet to young, male, foreign-born Latinos migrating in search of economic opportunities."

Card and Lewis (2005) analyze the spread of Mexican immigrants beyond the traditional destination cities in California and Texas to "new" destinations like Atlanta, Georgia, Denver, Colorado, Portland, Oregon, and Raleigh-Durham, North Carolina. They are surprised by how these flows to "new" destinations parallel the growth of employment without very large changes in wage rates in those destination economies. Card and Lewis conclude that they are "left with the 'puzzle' of explaining the remarkable flexibility of employment demand in different cities to local variations in supply." Is this a case of immigrants arriving and jobs then suddenly appearing to employ them? Or do the immigrants respond quickly to the opening of new jobs in these "new" destination cities? 


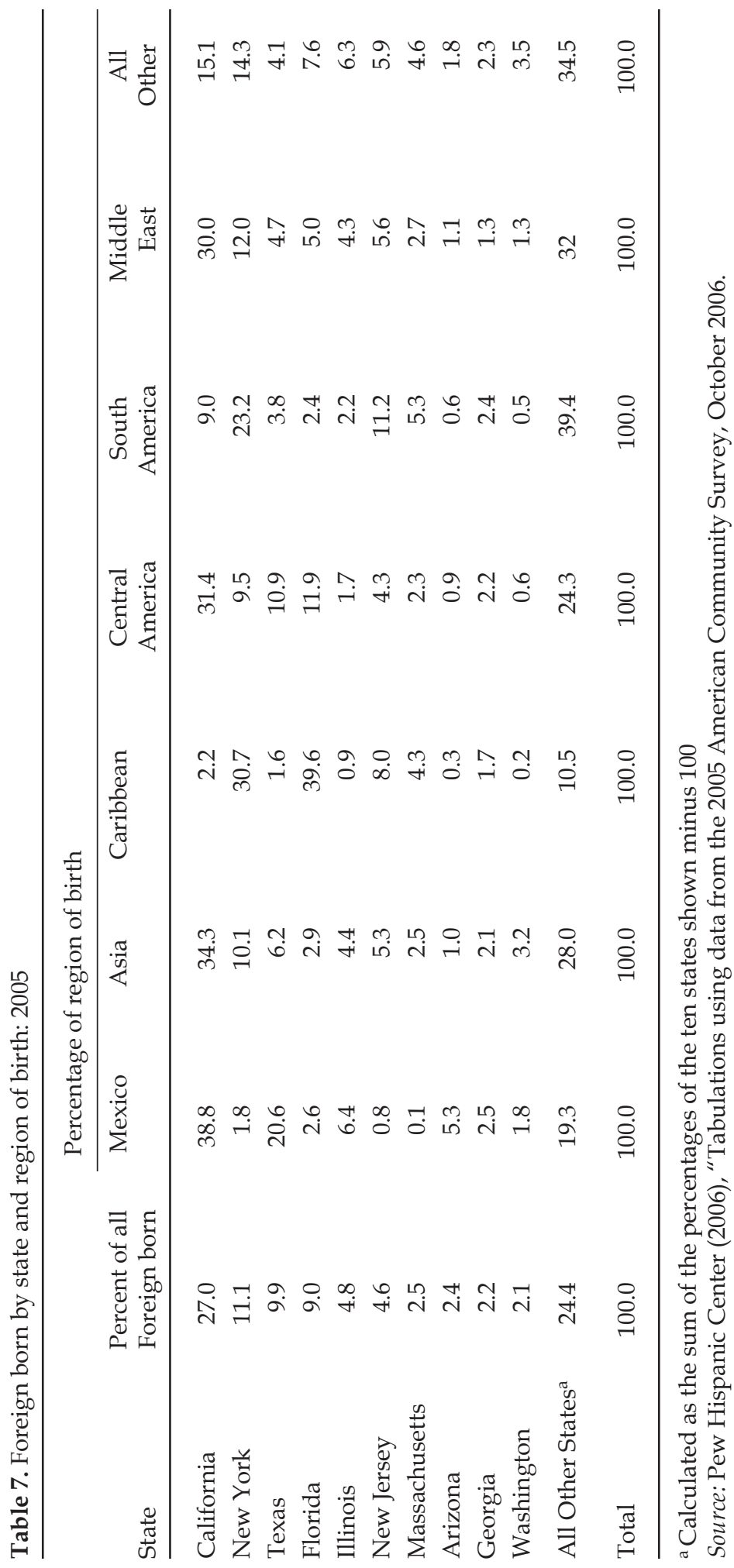


Table 8. Hispanic population change in the U.S.: 1990-2000

\begin{tabular}{lrrr}
\hline & Hispanics 1990 & Hispanics 2000 & \% Change \\
\hline 6 Southern states & 293,445 & $1,195,800$ & 308 \\
North Carolina & 76,726 & 378,963 & 394 \\
Arkansas & 19,876 & 86,866 & 337 \\
Georgia & 108,922 & 435,227 & 300 \\
Tennessee & 32,741 & 123,838 & 278 \\
South Carolina & 30,551 & 95,076 & 211 \\
Alabama & 24,629 & 75,830 & 208 \\
Traditional settlement states & $11,546,271$ & $16,481,592$ & 43 \\
California & $7,687,938$ & $10,966,556$ & 43 \\
New York & $2,214,026$ & $2,867,583$ & 30 \\
Illinois & 904,446 & $1,530,262$ & 69 \\
New Jersey & 739,861 & $1,117,191$ & 51 \\
\hline
\end{tabular}

Source: Table 2 from Kochlar, Suro, and Tafoya (2005).

\subsection{The Dispersal of Manufacturing Jobs and Immigrant Dispersal}

This dispersal of the growing number of Hispanic immigrants is not such a puzzle when it is viewed in light of the gradual shifts in manufacturing activity in the U.S. over the past half century. Hispanic immigrants have largely followed the dispersion of manufacturing activity to rural areas in the South, Midwest, and Great Plains regions. The current shift of manufacturing from the traditional manufacturing centers to rural regions of the American Midwest and Great Plains is fundamentally a continuation of the earlier trends that saw manufacturing shift from the traditional urban centers of the Northeast and North central regions of the country toward those regions in the South where wages are lower and unions are less powerful. The current growth of manufacturing in traditionally agricultural communities is also being driven by the arrival of foreign firms setting up manufacturing in the U.S. for the first time. These foreign greenfield investments similarly seek low labor costs, lower living costs for prospective employees, and business friendly environments.

This geographic shift in manufacturing has been well documented and studied. However, commentators and researchers have largely overlooked a very important detail about the growth of manufacturing in rural America: The revival of the rural South, Midwest, and Great Plains depends on foreign immigrants. The people moving in to take the new manufacturing jobs are often recent immigrants, and a substantial portion of them are undocumented. Rural communities in the United States enjoy a comparative advantage in infrastructure and location; the United States' mod- 
ern transportation infrastructure places most rural communities within the distribution systems serving the U.S. market for most products. The only thing lacking in these communities is a large labor force. Immigration effectively provides this missing labor force. The fact that it is manufacturing that is driving the immigration flows is compatible with the observation that the "new" immigrant destinations are not seeing a reduction in white and black populations; to the contrary, the main immigrant destinations are experiencing increases in new black and white populations as well. For example, Kochlar, Suro, and Tafoya (2005) report that even in the six Southern states, where Hispanic populations grew so rapidly, white and black populations still grew by 11 and 21\%, respectively, from much higher bases over the same 1990-2000 period.

It is immigration that is the key to the growth of manufacturing in rural communities in the U.S. There is a seemingly endless "reserve army of labor" in the developing economies of the world. Their distant locations, poorly developed transportation systems, and lack of human and physical capital are all factors that have kept returns to labor very low in those countries. Failing institutions, furthermore, cause economic failures and unemployment. Modern communications and cheap transport make it increasingly possible for labor to move across borders in response to wage differences. Hence, producers prefer to operate in the U.S. where infrastructure is ample and distances to markets are short.

Our broad model of technological progress and shifting production patterns suggests that rural communities in areas like Appalachia and the Great Plains would not be able to reverse their declines without immigration. Indeed, if manufacturing continues to face increasing labor costs in the highly agglomerated urban regions of the United States, manufacturers and producers of services will increasingly look to lower cost locations. If low cost labor is not available somewhere within the U.S., the likelihood increases that manufacturing will instead move to China, India, or Brazil. In this case, the rural economies of Appalachia and the Great Plains will not enjoy their revival, and their economic decline will continue. The U.S. will have a smaller population as a result, and geographic agglomeration will likely actually increase. Overall U.S. GDP will be lower, and the Americans working in the agglomerated sectors will have lower incomes.

The U.S. press has been full of stories about the changes brought to the "new" immigrant destinations. For example, The Wall Street Journal described Dalton, Georgia, the home of three major carpet manufacturing plants, Shaw Industries Inc., Mohawk Industries Inc., and Beaulieu of America LLC. Job opportunities for immigrants are plentiful in Dalton. The U.S. carpet industry faces a situation similar to that of many U.S. industries faced with international competition and an increasingly scarce native work force:

It didn't make sense to leave. Carpet mills here have made huge investment in giant tufting machines that stitch yarn into plastic backing and dye tanks that soak color into bolts of weave the length of football fields. If the mills cut labor costs by moving offshore, they'd still face the extra expense of shipping heavy carpet back to their major market. Dalton is within a 24 -hour drive of about $85 \%$ of all U.S. buyers. Industry consolidation over the past two decades strengthened carpet makers' ties to the area, not 
only making Dalton a one-industry town but also making Dalton a one-town industry. So, with the industry's roots entrenched, Mexico has come to Dalton. ${ }^{11}$

The community is changing along with the carpet industry's workforce. In 2000, one-third of the children born in Dalton's Hamilton Medical Center were from Hispanic families. There were 12,000 Hispanics in Dalton in 2000, and they have become noticeable in the community:

The sights and sounds of rural Mexico are everywhere along Dalton's main drag, Walnut Street, where accordion-rich music from Mexico's north blares from quick-stop taco shops. Poster and fliers in Spanish tout at least 10 different agencies offering ways for recent migrants to send money home. Each morning, a refrigerator truck of an Atlanta-based food distributor, Al Maizal, darts in and out of the local strip malls, stocking more than two dozen Mexican restaurants and convenience stores. Florists, funeral homes and pharmacies all promise walk-in customers that "se habla espanol"12

Not everyone in Dalton is happy about the changes their community is going through. Some years ago, the local newspaper had to stop running letters to the editor about immigration because the tone had gotten too angry. "Quit employing them, quit renting to them, quit educating them," wrote one local citizen back in 1995. In 2005, over half the incoming kindergarten students were Hispanic.

\section{Explaining Hispanic Immigration}

According to Card and Lewis (2005), Mexican immigration to the U.S. was driven, on the supply side, by population growth, falling real wages, and persistently weak economic conditions in Mexico. They also point out that immigrants tend to follow prior immigrants from the same cities and regions, and they find that prior immigrants also explain the supply of Mexican immigrants to the various regions of the U.S. On the demand side, they hypothesize that immigrants are attracted by employment and wages. They find that supply side factors explain $75 \%$ of the variation in immigration, demand factors only another 10\%. In fact, they find that after 1990, demand factors are not significant in explaining inflows of Mexican immigrants; only supply push and prior flows determine immigrant inflows into specific counties in the U.S. Similarly, Richter, Taylor, and Yunes-Naude (2006) find that the effects of changes in U.S. immigration policy or macroeconomic conditions on Mexican immigration to the U.S. are small compared to the network effects.

There were some special events that help to explain the surge in Hispanic immigration to the U.S. For example, Martin (2004) describes how unauthorized immigration from Mexico to the United States grew after the ratification of the North American Free Trade Agreement (NAFTA) because free trade in corn pushed many Mexican 
farmers off the land. Corn production in Mexico had been protected from imports, and a domestic price twice the world price had for years served as a social safety net in rural Mexico. When NAFTA came into effect in the mid-1990s, Mexico had about 3 million corn farmers. This compared to the 75,000 corn farmers in just the state of Iowa in the United States, who produced nearly twice as much corn as Mexico at half the price. In part, the U.S. price of corn was low because of the U.S. government's direct subsidies and years of indirect subsidies through technical extension services and federally funded university research. It was not long after the establishment of free trade between the U.S. and Mexico that Mexican corn farmers abandoned their farms in great numbers. Many of these farmers migrated to the United States, most illegally. Richter, Taylor, and Yunez-Naude (2006) dispute this explanation of unauthorized Mexican immigration, however. Their statistical results do not give NAFTA a major role in driving Mexican immigration to the United States; as reported above, they find that overall macroeconomic trends in Mexico and the U.S. and immigrant network effects dominate in explaining immigrant flows.

\subsection{The Welfare Effects on the Source Hispanic Countries}

There has been little analysis of how the large outflows of Hispanic immigrants to the U.S. have affected the source economies. Clearly, the large numbers of people involved suggest that the effects of the departure of so many people must have been substantial. For example, since the civil war in the 1980s, the rise in crime, and the brutal government crackdowns on dissent in El Salvador, over 15\% of that Central American country has moved to the United States. Table 1 showed that there are about 11 million Mexican-born immigrants in the United States; that is more than 10\% of Mexico's current population.

Mishra (2006) applied immigration data for 1970 through 2000 in a standard theoretical framework, similar to the immigration model used throughout this book. She concludes that the departure of Mexican immigrants to the U.S. raised the wage of the average Mexican remaining in Mexico by about $8 \%$. The wage effects differ greatly depending on Mexicans' levels of education, however. The wages of Mexicans with less than a high school education rose by only $5 \%$, while the wages of high school graduates rose by about $15 \%$. The reason for this disparity in wage effects is that a higher proportion of the relatively small group of high school graduates left the country. The great majority of Mexican immigrants have less than a high school education, but an even greater majority of all Mexicans have not graduated from high school. Mishra also calculates that the overall effect of Mexican immigration to the United States is to reduce Mexico's 2000 GDP of $\$ 580$ billion by about one-half of $1 \%$, or $\$ 3$ billion. The gain for workers staying behind is $5.9 \%$ of GDP, and the loss to the owners of the fixed factors is about $6.4 \%$ of GDP. In terms of the standard labor market model of immigration for the source country, which was illustrated in Fig. I.4 in the Introduction to Part I, p. 24, the area $\mathrm{e}=5.9 \%$ of GDP, and the sum of $\mathrm{e}+\mathrm{g}=6.4 \%$ of Mexican GDP. 


\subsection{The Demand Effects of Hispanic Immigration}

The theoretical models of immigration discussed in earlier chapters suggest that immigrants have labor and product demand effects, as well as labor supply and complementary factor supply effects. The 41 million Hispanics in the United States clearly constitute a very large ethnic market. Spending by Hispanic households is estimated to exceed $8 \%$ of total household spending in the U.S. The size of this market will continue to grow with the above average birth rates for Hispanics in the U.S. Also, as incomes rise from first- to second-generation Hispanic immigrants, the market grows further. And, it will grow if Hispanic immigration to the U.S. continues growing.

It is interesting to note that marketers have suddenly recognized the importance of the Hispanics' product demand effect on the U.S. economy. The Bank of America Corp. has begun offering credit cards to customers without social security numbers. Advertising revenue at Univision, the large U.S. Spanish language television network, and its smaller rival Telemundo grew by over $20 \%$ per year in the early 2000s, about double the increase of overall television advertising revenue in the U.S. Marketers have been especially keen to identify themselves with Mexican holidays such as Cinco de Mayo. Corona beer, the Mexican brand that sells as a premium beer in the U.S., now uses cinco de Mayo to tout its Mexican heritage to all U.S. consumers, spending over $\$ 2$ million during the first week of May alone. ${ }^{13}$ Sears, Roebuck \& $\mathrm{Co}$. has recently begun to shift advertising expenditures from Cinco de Mayo to Mexican Independence Day on September 16 because it felt Cinco de Mayo was becoming too much of an "American" holiday, much the way St. Patrick's Day or Oktoberfest are enthusiastically celebrated by Americans of all ethnic backgrounds. ${ }^{14}$ Clearly, even though the simple labor market model of immigration does not recognize the growth in demand after the arrival of immigrants, the firms that supply the U.S. market certainly do.

\section{Future Hispanic Immigration}

Mexico's Ministry of the Interior did a study on the future of Mexican immigration to the United States. This study, prepared by the Ministry's Consejo Nacional de Población (2001), provided alternative estimates under different assumptions about economic growth in Mexico and the U.S. as well as different assumptions about future population growth in Mexico. The study concludes that with rapid economic growth 
in Mexico and moderate growth in the demand for labor in the U.S., Mexican immigration to the U.S. will remain steady at about 400,000 per year. Such annual flows of immigrants imply that another 10 million Mexican immigrants will arrive in the U.S. by the year 2030. On the other hand, slow economic growth in Mexico and robust labor demand in the U.S. would swell Mexican immigration to over half a million per year by 2030.

The study's conclusions reflect some of the empirical studies of Hispanic immigration discussed earlier in this chapter:

The narrow range in which these situations vary indicate that other factors closely related to the migration tradition of more than 100 years and the operation of complex social networks are apparently more determinative of international emigration than the impact of economic fluctuations in the labor markets in both countries. ${ }^{15}$

In other words, most future immigrant flows from Mexico to the U.S. are inevitable. Simcox (2002) attributes the government study's conclusions to international politics: the alleged inevitability of more immigration could be used by Mexico to pressure the U.S. government into adapting a more comprehensive immigration policy that permits more Mexicans to enter the U.S. legally. However, the Mexican government's study does not conflict with existing evidence on immigration.

\subsection{Will Hispanic Immigration Continue?}

Not all studies predict continually increasing immigration flows from Mexico and other Latin American countries. The fact is that population growth in Latin America is slowing rapidly. This means that 20 years from now, there will be fewer young workers. As already pointed out at the start of this chapter, Hispanic immigrants to the U.S. are disproportionately young and of working age, which has to some degree mitigated the problems associated with the ageing of U.S. society. But, it appears that Hispanic countries will not have as many young people to send to the U.S. in the future. Also, the currently young Hispanic population will age too, and Hispanics will eventually reach retirement age.

Table 9 presents alternative estimates of the future size of the Hispanic population in the U.S. by Roberto Suro and Jeffrey Passel of the Pew Hispanic Center. The number of Hispanic immigrants is predicted to continue growing, and the growth is spread across first, second, and third generation Hispanics. These predictions suggest that Hispanics will have a strong impact on the U.S. economy and U.S. society in the future. The growing size of the Hispanic community in the U.S. will, no doubt, lead to increased interest in assimilation. Time will tell whether the Hispanic population in the U.S. will increase its rate of assimilation or whether the sheer size of the Hispanic community will continue to hamper the assimilation process. 
Table 9. Alternative immigration scenarios for Hispanics: 2000-2020

\begin{tabular}{lllll}
\hline & $\begin{array}{l}\text { Total } \\
\text { Hispanic }\end{array}$ & $\begin{array}{l}\text { 1st } \\
\text { generation }\end{array}$ & $\begin{array}{l}\text { 2nd } \\
\text { generation }\end{array}$ & $\begin{array}{l}\text { 3rd } \\
\text { generation }\end{array}$ \\
\hline \multicolumn{2}{l}{ Mid-range estimate: } & & & \\
2000 & $35,306,000$ & $14,158,000$ & $9,887,000$ & $11,261,000$ \\
2010 & $47,696,000$ & $18,126,000$ & $15,404,000$ & $14,167,000$ \\
2020 & $60,424,000$ & $20,555,000$ & $21,659,000$ & $18,210,000$ \\
High-range Estimate: & & & \\
2000 & $35,306,000$ & $14,158,000$ & $9,887,000$ & $11,261,000$ \\
2010 & $51,013,000$ & $20,761,000$ & $16,086,000$ & $14,167,000$ \\
2020 & $67,282,000$ & $25,090,000$ & $23,970,000$ & $18,221,000$ \\
\hline
\end{tabular}

Source: Table 3 from Suro and Passel (2003).

\subsection{Temporary Immigration Programs}

There have been suggestions that the U.S. should combat unauthorized immigration by instituting temporary immigration programs, such as the Bracero Program after World War II. Temporary immigration programs in Europe ended up increasing the permanent immigrant populations of many European countries, however. In order to assess whether temporary worker programs in the U.S. will end up reducing the unauthorized entry of Hispanic immigrants without adding to the further growth of the permanent Hispanic population, it is informative to look at a recent opinion survey of Hispanic immigrants by the Pew Hispanic Center described in Suro (2005).

The survey covers a large number of Mexican immigrants who visited a Mexican consulate in the U.S. in 2004 in order to apply for a matricula consular, the widely used identity card issued by the Mexican government. Most Mexicans applying for such cards are unauthorized immigrants unable to gain U.S. documents. Therefore, the survey clearly presents a biased sample of Mexican immigrants. Mexicans who would normally immigrate illegally would be the primary applicants for temporary work visas if they were made available.

The survey results show that by a 4 to 1 margin, respondents said they would participate in a temporary worker program that would allow Mexicans to work in the U.S. for a limited number of years and then return permanently to Mexico. Yet, $42 \%$ of the respondents replied they would stay in the U.S. "As long as I can" and another 17\% said they wanted to stay "for the rest of my life." Only $27 \%$ said they intended to stay for less than 5 years. About three out of four respondents said they would participate in a program that offered the prospect of permanent legalization of unauthorized immigrants. In short, one could reasonably expect that many participants in any temporary immigration scheme would do what they could to remain in the U.S. when their temporary permit expired. Like what happened in Europe in the 1960s, many guest workers would become permanent residents and citizens. 


\section{Conclusions}

This chapter has presented some of the exceptional characteristics of the recent Hispanic immigration to the United States. In 2005, there were nearly 40 million Hispanic immigrants and descendants of Hispanic immigrants living in the U.S. The assimilation experience of this large cultural group does not seem to have followed the path past immigrants to the U.S. followed, and even most third generation Hispanics in the U.S. still find themselves with income and education levels substantially below the U.S. averages. Some forecasts predict that as many as 60 million Hispanics will be living in the U.S. by 2020. It is no wonder that many Americans worry about the cultural effects of Hispanic immigration.

Few other countries in the world are experiencing such a large inflows of people from a single foreign culture. Even if we recognize, and we should, that not all Hispanics are similar, it is still the case that nearly $60 \%$ of all Hispanic immigrants and descendants are from a single country, Mexico. Sociologists have studied Hispanic immigration much more thoroughly than economists because the cultural implications are so important. However, economists also need to pay more attention to Hispanic immigration because the size of Hispanic immigration implies that assimilation is likely to be much slower than would normally be the case for smaller immigrant groups. The slower pace of assimilation has very real economic implications. Also, the expansion of Hispanic ethnic enclaves has clear demand side implications. American business has already effectively recognized this in the form of more focused marketing aimed at the Hispanic market. It may also be interesting to study whether the predominantly Hispanic immigration to the United States brings substantially different outcomes compared to the more diverse immigration into the high income countries of Europe and to Canada or the greater Asian immigration flows to Australia, for example. In any case, the study of Hispanic immigration should not belong exclusively to sociologists.

Finally, the following quote helps to keep the often-emotional discussions of Hispanic immigration in a broader perspective:

\footnotetext{
Few of their children in the country learn English ... The signs in our streets have inscriptions in both languages ... Unless the stream of their importation could be turned they will soon so outnumber us that all the advantages we have will not be able to preserve our language, and even our government will become precarious. ${ }^{16}$
}

These words seem to represent the sentiments often displayed toward Hispanic immigration by commentators and Americans on the street. You will be interested to know that they were written nearly 250 years ago by Benjamin Franklin! Franklin was referring to German immigrants who had arrived in Pennsylvania in the 1750s! Those German immigrants, or at least their descendants, were eventually fully absorbed into 
U.S. society, and few Americans today could imagine why anyone would make such a fuss about German immigrants. Time will tell whether the fear that pervades discussions of Hispanic immigrants will eventually be looked back on as having been just as misguided as Benjamin Franklin's assessment of the Germans in eighteenth century Pennsylvania.

\section{References}

Authers, J. (2004, 1 July). Tomato King looks to make mark for Mexican migrants. Financial Times.

Bauer, T., Epstein, G., \& Gang, I. N. (2002). Herd effects or migration networks? The location choice of Mexican immigrants in the U.S. IZA Discussion Paper No. 551, August.

Bernstein, N. (2004, 5 December). Dominican President visits, reaching out to diaspora. New York Times.

Blau, F. (1980). Immigration and labor earnings in early twentieth century America. Research in Population Economics, 2, 21-41.

Blau, F., \& Kahn, L. (2005). Gender and assimilation among Mexican Americans. In G. Borjas (Ed.), Mexican Immigration. Chicago: University of Chicago Press.

Borjas, G. (1994). The economics of immigration. Journal of Economic Literature, 32(4),1667-1717.

Borjas, G. (1985). Assimilation, changes in cohort quality, and the earnings of immigrants. Journal of Labor Economics, 3, 463-89.

Card, D., \& Lewis, E. (2005). The diffusion of Mexican immigrants during the 1990s: Explanations and impacts. NBER Working Paper No. 11552, August.

Chiswick, B. (1978). The effect of Americanization on the earnings of foreign-born men. Journal of Political Economy, 86(5), 897-921.

Chiswick, B. (2000). Are immigrants favorably self-selected? An economic analysis. IZA Discussion Paper No. 131, March, 2000.

Consejo Nacional de Población, Dirección de Communicación Social (2001). Migración méxico-estados unidos 2001. Mexico City: November.

Davis, K. C. (2007, 3 July) The founding immigrants. New York Times.

Duncan, B., \& Trejo, S. (2006). Ethnic identification, intermarriage, and unmeasured progress by Mexican Americans. In G. Borjas, (Ed.), Mexican Immigration. Chicago: University of Chicago Press.

Fairlie, R., \& Woodruff, C. (2006). Mexican entrepreneurship: A comparison of self-employment in Mexico and the United States. In G. Borjas, (Ed.), Mexican Immigration. Chicago: University of Chicago Press.

Huntington, S. (2004). The Hispanic challenge. Foreign Policy March/ April.

Jasso, G., \& Rosenzweig, M. (1988). How well do U.S. immigrants do? Vintage effects, emigration selectivity, and occupational mobility. Research in Population Economics, 6, 229-253. 
Kochlar, R., Suro, R., \& Tafoya, T. (2005). The new Latino South: The context and consequences of rapid population growth. Pew Hispanic Center Report, July 26.

Lazear, E. P. (2006). Mexican assimilation in the United States. In G. Borjas, (Ed.), Mexican Immigration. Chicago: University of Chicago Press.

Livingston, G., \& Kahn, J. (2002). An American dream unfilled: The limited mobility of Mexican Americans. Social Science Quarterly, 83(4), 1003-1012.

Martin, P. (2004). Mexican migration to the United States: The effect of NAFTA. Chapter 7 in D. Massey, J. E.\& Taylor(Eds.), International migration: Prospects and policies in a global market (pp. 120-130). Oxford: Oxford University Press.

Millman, J. (2001, 1 May). U.S. marketers adopt cinco de mayo as National fiesta. Wall Street Journal.

Millman, J., \& Pinkston, W. (2001, 30 August). Mexicans transform a town in Georgiaand an entire industry. Wall Street Journal.

Mishra, P. (2006). Emigration and wages in source countries: Evidence from Mexico. IMF Working Paper WP/06/86, International Monetary Fund, March.

Pascal, G. Z. (1998, 25 March). Dual citizenship is double-edged sword. The Wall Street Journal,

Pew Hispanic Center (2006). Tabulations using data from the 2005 American Community Survey. October.

Perlmann, J., \& Waldinger, R. (1997). Second generation decline? Children of immigrants, past and present - a reconsideration. International Migration Review, 31(4), 893-922.

Richter, S., Taylor, J. E., \& Yunez-Naude, A. (2006). Impacts of policy reforms on labor migration from rural Mexico to the United States. In G. Borjas, (Ed.), Mexican Immigration. Chicago: University of Chicago Press.

Simcox, D. (2002). Another 50 years of mass Mexican immigration. Center for Immigration Studies, March.

Suro, R. (2002). Counting the 'other Hispanics': How many Colombians, Dominicans, Ecuadorians, Guatemalans and Salvadorans are there in the United States? Report by the Pew Hispanic Center, May 9.

Suro, R. (2005). Survey of Mexican migrants, part two-attitudes about voting in Mexican elections and ties to Mexico. Pew Hispanic Center, March 14.

Suro, R., \& Passel, J. S. (2003). The rise of the second generation: Changing patterns in Hispanic population growth. Pew Hispanic Center Study, October.

Trejo, S. J. (1997). Why do Mexican Americans earn low wages. Journal of Political Economy, 105(6), 1235-1268.

Trejo, S. J. (2003). Intergenerational progress of Mexican-origin workers in the U.S. labor market. Journal of Human Resources, 38(3), 467-489.

Weiner, T. (2004, 16 June) Fox seeks to allow Mexicans living abroad to vote in 2006. Wall Street Journal.

Yuengert, A. M. (1995). Testing hypotheses of immigration self-employment. Journal of Human Resources, 30(1),194-204. 